\title{
Static and Dynamic Analysis of Railway Reinforced System with Cross-Beams
}

\author{
Bin Peng, ${ }^{1,2}$ Nan Zhang, ${ }^{1}$ and Yu Lan Gao ${ }^{2}$ \\ ${ }^{1}$ School of Civil Engineering, Beijing Jiaotong University, Beijing 100044, China \\ ${ }^{2}$ China Railway Engineering Consulting Group Co., Ltd., Beijing 100055, China \\ Correspondence should be addressed to Nan Zhang; nzhang@bjtu.edu.cn
}

Received 14 November 2013; Accepted 7 March 2014; Published 9 April 2014

Academic Editor: Rui Mu

Copyright (c) 2014 Bin Peng et al. This is an open access article distributed under the Creative Commons Attribution License, which permits unrestricted use, distribution, and reproduction in any medium, provided the original work is properly cited.

To fulfill the design requirement of railway reinforced system with cross-beams, the model for the static analysis of the railway reinforced system is optimized, the dynamic response is calculated by the vehicle-rail interaction method, the standards of both static and dynamic analysis are established, and the calculation results of many cases with different parameters are evaluated. It is found that, compared with simplified model, the optimized model simulated the conditions of construction site better, so that results are improved; the acceleration and the offloading factor of reinforced system is obtained by the dynamic analysis, whose vibration and resonance phenomenon can be simulated. The calculated result and the railway reinforcement design are safer by adopting the proposed standard in both static and dynamic analysis.

\section{Introduction}

Most cities in China are experiencing a rapid increase in motor ownership, which leads to a rising congestion, air pollution, and high energy consumption. The developments of public transportation systems are given priority to solve or improve these urban transportation problems [1-4]. Urban railway system is considered an effective way to improve trip structure and alleviate traffic congestion problem in metropolis due to its high capacity and efficiency. Thus, urban railway is developing fast in recent years.

However, in the cities crossed by railway, problems also exist, plane crossroads formed by railway and roads did not make traffic better, jams or even accidents are usually happen in these areas, while the appearance of frame underpass bridge alleviates the problem, it makes the traffic more fluent by separating railway and roads, which establishes interchange.

There are few frame bridge jacking constructions outside of China, the main reason is that, trains running in other countries' railway are usually not as many or frequent as in China, which makes the railway line under construction of frame bridge can be closed temporarily, while in China, railway transport ability still need to be improved even after the rapid development for many years, the railway line under construction of frame bridge can not be closed, and the trains have to pass the construction site in a certain velocity. From many methods of constructing frame underpass bridge, jacking method is a main way, which needs the railway reinforced system to ensure the safety of passing trains, therefore, cases of railway reinforced system construction are also common in China, and combined with these cases, junior design theory is formed.

However, specifications and codes nowadays seldom mention regulations about railway reinforced system, the design of railway reinforced system mostly bases on experience concluded from similar constructions, although some design work calculate with simplified model $[5,6]$, flaws still exist in following aspects:

(1) simplified model neglects the impact of rail, longitudinal beam, and track fastener, and applies uniform load converted from "China railway standard live loading" on transverse beam; it is supposed that the transverse beam as simply supported beam and recognized as safe. In fact, in code of "China railway standard live loading," the transverse beam right under the midwheel is obviously under the pressure of 


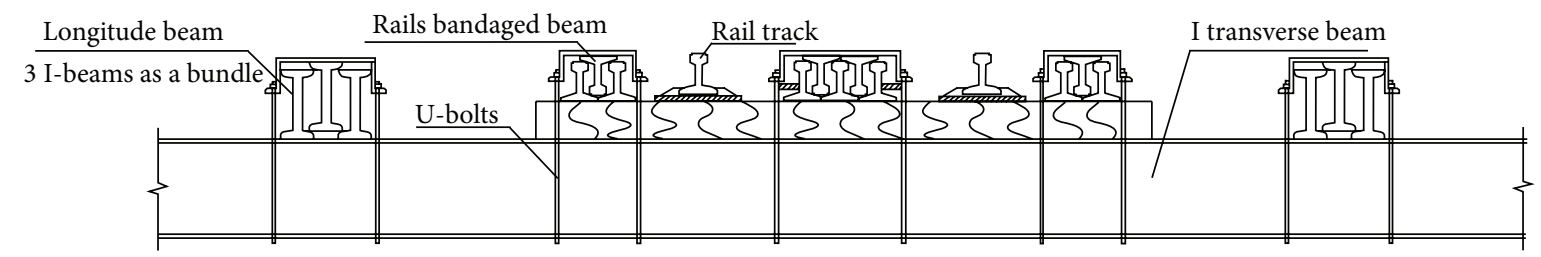

FIGURE 1: Section scheme of railway reinforced system with cross-beams.

lateral wheel, while longitudinal beam is the member transferring load. Also the deflection of transverse beam is measured by millimeters; the deformation of supporting ends (frame bridge and excavated soil) cannot be ignored. Therefore, longitudinal beam and supporting ends should be simulated in the model,

(2) standards of calculation results on railway reinforced system come from different sources and mainly contain regulations in the scope of railway bridge, railway track, and building structure,

(3) the vibration of railway reinforced system caused by train dynamic load is not simulated. Dynamic load of passing train will motivate vibration of the railway reinforced system; resonance phenomenon might be provoked if frequency of dynamic load and railway reinforced system is close to each other; then amplitude of reinforced system will be largely increased, so dynamic analysis should be introduced to simulate the phenomenon.

The design of railway reinforced system concerns safety of peoples' lives and fortune; therefore, improving and optimizing calculation model and introducing dynamic analysis which can simulate dynamic response and building improved research system have great significance, so that construction theory can be provided. Section scheme of railway reinforced system with cross-beams is shown in Figure 1.

In this paper, three-dimensional model with longitudinal members is established as static calculation model; the impact of frame bridge and excavated soil supporting the reinforced system is considered; the dynamic response is calculated by the vehicle-rail interaction method; the standards of both static and dynamic analysis are established and the calculation results of many cases with different parameters are evaluated. It is found that, compared with simplified model, the optimized model simulated the conditions of construction site better, so that results are improved; the acceleration and the offloading factor of reinforced system is obtained by the dynamic analysis, whose vibration and resonance phenomenon can be simulated; the calculated result and the railway reinforcement design are safer by adopting the proposed standard in both static and dynamic analysis.

\section{Static Calculations}

2.1. Calculation Conditions and Parameters Selection. 12 cases with different parameters of beam size, span, and velocity
TABLE 1: Calculation conditions.

\begin{tabular}{|c|c|c|c|}
\hline \multirow{2}{*}{ Conditions } & \multicolumn{3}{|c|}{ Parameter } \\
\hline & Span/m & Steel I-beamsize & Velocity $/ \mathrm{km} / \mathrm{h}$ \\
\hline $1 / 2 / 3 / 4$ & 4 & $\mathrm{I} 45 \mathrm{c}$ & $45 / 50 / 55 / 60$ \\
\hline $5 / 6 / 7 / 8$ & 5 & $\mathrm{I} 56 \mathrm{~b}$ & $45 / 50 / 55 / 60$ \\
\hline 9/10/11/12 & 6 & $\mathrm{I} 63 \mathrm{~b}$ & $45 / 50 / 55 / 60$ \\
\hline
\end{tabular}

TABLE 2: Ratio of beam deflection.

\begin{tabular}{lcccccccc}
\hline $\begin{array}{l}\text { Coordinate of } \\
\text { beam }\end{array}$ & $-2.7 \mathrm{~m}$ & $-1.8 \mathrm{~m}$ & $-0.9 \mathrm{~m}$ & $0 \mathrm{~m}$ & $0.9 \mathrm{~m}$ & $1.8 \mathrm{~m}$ & $2.7 \mathrm{~m}$ \\
\hline $\begin{array}{l}\text { Ratio of beam } \\
\text { deflection }\end{array}$ & 1 & 18 & 53 & 81 & 53 & 18 & 1 \\
\hline
\end{tabular}

of train are established. Cases and parameters are listed in Table 1. Three-dimension model with railway, longitudinal beam, track-locking, some cross-beams, frame bridge, and excavated soil are established and simulated in finite element software ABAQUS; in the model, rail tracks are located in the middle of beam span; "China railway standard live loading" is applied on rail with middle wheel right above the researched beam. Other parameters of model include rail track weighing $50 \mathrm{~kg} / \mathrm{m}$, I45b longitudinal beam with 3 beams as a bundle, 3-5-3 track-locking, and I63b transverse beam; the distance of adjacent transverse beams is $0.9 \mathrm{~m}$.

To simulate transverse beams and to ensure the calculation model is accepted by the software so that calculation process will converge, define the number of transverse beams by the following method: establishing a model including rail, longitudinal beam, and some cross-beams; applying load on rail; and simulating the midspan deflection; then cooperation work ability of transverse beams can be evaluated. As torsional stiffness of longitudinal beam restrains the bending of transverse beam, assume rotational inertia of longitudinal beam as 1. Deflection ratios of beams are listed in Table 2.

It can be concluded from calculation results above that longitudinal members coordinate the deformation of transverse beams and share train load to a certain extent; however, the deflection of transverse beam $2.7 \mathrm{~m}$ far from researched beam takes only $1.23 \%$ of the researched beam's deflection; therefore, only some transverse beams need to be simulated; for safety consideration, 11 transverse beams in 9-meter range are taken.

To simulate the deformation of railway reinforced system caused by supporting ends, a frame bridge model is built on the bridge side; its constitutive relation is defined as ideal elastic-plastic model without strengthening segment; 


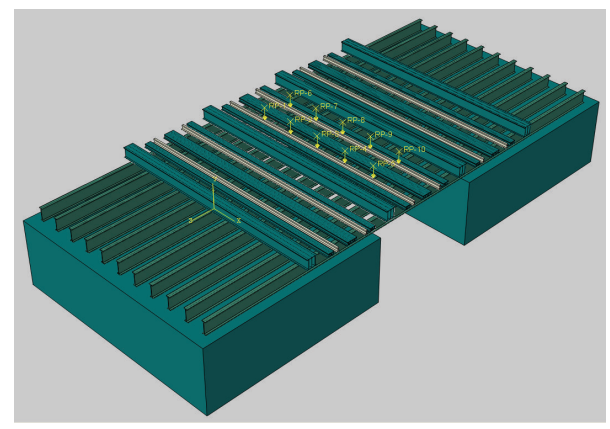

Figure 2: Calculation model.

TABLE 3: Unilateral wheel load under different parameters (unit: $\mathrm{kN})$.

\begin{tabular}{lcccc}
\hline \multirow{2}{*}{ Span } & \multicolumn{4}{c}{ Velocity } \\
& $45 \mathrm{~km} / \mathrm{h}$ & $50 \mathrm{~km} / \mathrm{h}$ & $55 \mathrm{~km} / \mathrm{h}$ & $60 \mathrm{~km} / \mathrm{h}$ \\
\hline $4 \mathrm{~m}$ & 148.34 & 164.82 & 181.31 & 197.79 \\
$5 \mathrm{~m}$ & 147.06 & 163.40 & 179.74 & 196.08 \\
$6 \mathrm{~m}$ & 145.83 & 162.04 & 178.24 & 194.44 \\
\hline
\end{tabular}

the contact pair is built between transverse beams and frame bridge; excavated soil model is built on the soil side, considering the transverse beams embedded in trench and supported by the fender pile at the end side; relationship of attachment is built between soil and transverse beam, whereas the roadbed of railway filled by A or B fillings or modified soil is relatively representative; excavated soil is defined as elastic; the parameters' values are taken with reference to parameters of A or B fillings or modified soil in "design guideline of ballastless track of passenger dedicated railway line." The calculation model is shown in Figure 2.

2.2. Load Calculation. Apply locomotive load of "China railway standard live loading" on railway reinforced system; for safety consideration, take $25 \mathrm{t}$ as axle load. To simulate dynamic increment of train load, take axle load multiplied by dynamic coefficient, reduction coefficient, and nonuniformity coefficient as actual load; take 1.3 as nonuniformity coefficient; dynamic coefficient and reduction coefficient are functions of beam span and speed, whose calculation formulas with reference to formulas in "code for design on steel structure of railway bridge." Values of unilateral wheel's load of different cases are listed in Table 3.

\subsection{Calculation Results and Evaluation. Results of cases are} listed in Table 4.

In current research of static simulation on railway reinforced system with cross-beams, the evaluation of calculation results takes stress and deflection of transverse beam as indexes, while standards of indexes come from different sources; whereas railway reinforced system has characters of railway and railway bridge, regulations of both scopes should be investigated. Besides, there are correlative regulations in the "code for design of steel structures," which should be also adopted in the evaluation standard. By comparing, analyzing and concluding relevant regulations from 6 specifications or codes, we think evaluation standards of railway reinforced system with cross beams should contain indexes as follows: stress, deflection of I-beam, and deformation of rail. In consideration of safety, take the minimum number as the evaluation standard. Indexes and standards are listed in Table 5 .

It can be concluded from Tables 4 and 5 that, in 12 cases, every index meets the requirement of evaluation standard.

\section{Dynamic Calculation}

3.1. Vehicle-Railway Coupling Analysis Theory. There are three ways to solve the vehicle-railway coupling system in the previous studies.

(1) Moving Loads. In most of early studies [7, 8], the effect of vehicle is adopted by a series of moving loads, in which the dynamic interaction between vehicle and railway is ignored. The method is fit for the cases where the vehicle and the railway have large stiffness or mass differences. Only static vehicle loads and vertical railway response are considered in these studies.

(2) Vehicle-Railway Iteration. This kind of methods was developed in the recent 20 years [9-12]. Both the vehicle and the railway are modeled in the method and two independent equations are established, which is solved by history integral. The two subsystems of vehicle and railway are linked by the predefined wheel-rail motion-force relationship. The motion status of both subsystems is fulfilled by the iteration calculation within time steps in the history integral. The method is widely used and can fit for complex and nonlinear cases.

(3) Vehicle-Railway Simultaneous Equations [13, 14]. The subsystems of vehicle and railway are combined into the global equations in kind of methods; thus the iteration between vehicle equations and railway equations is avoided [15-17]. The nondiagonal parts of the global mass, damping, and stiffness matrices are derived from the wheel-rail relation; thus the linear relationship is required in the wheel-rail motion-force.

The process of moving loads is unconditional convergent if an unconditional convergent history integral method is used; but, for a method containing 2 or more subsystems, the process is no more unconditional convergent; even unconditional convergent integral method is used, as shown in $[18,19]$. Many cases are found unconvergent for the methods (2) and the methods (3) above.

In this paper, an intersystem iteration (ISI) method is used; in the method, the dynamic responses of vehicle subsystem and rail subsystem are solved separately, the iteration within time-step is avoided, the computation memory can be saved, and the programming difficulty is reduced.

In the ISI method, firstly, the subsystem of reinforced system is assumed rigid, while the vehicle motion and wheel-rail force histories are solved by the independent vehicle subsystem for the complete simulation time; then 
TABLE 4: Calculation results.

\begin{tabular}{|c|c|c|c|c|c|}
\hline Span/m & Beam size & Velocity $/ \mathrm{km} / \mathrm{h}$ & Beam deflection $/ \mathrm{mm}$ & Rail deflection/mm & Stress/MPa \\
\hline 4 & $\mathrm{I} 45 \mathrm{c}$ & 45 & 4.41 & 4.20 & 63.24 \\
\hline 4 & $\mathrm{I} 45 \mathrm{c}$ & 50 & 4.95 & 4.73 & 70.83 \\
\hline 4 & $\mathrm{I} 45 \mathrm{c}$ & 60 & 5.47 & 5.23 & 78.29 \\
\hline 4 & $\mathrm{I} 45 \mathrm{c}$ & 65 & 6.00 & 5.74 & 85.84 \\
\hline 5 & I56b & 45 & 4.43 & 4.43 & 54.56 \\
\hline 5 & I56b & 50 & 4.94 & 4.93 & 60.51 \\
\hline 5 & I56b & 60 & 5.45 & 5.44 & 67.12 \\
\hline 5 & I56b & 65 & 5.96 & 5.95 & 73.40 \\
\hline 6 & $\mathrm{I} 63 \mathrm{~b}$ & 45 & 5.51 & 5.42 & 60.54 \\
\hline 6 & $\mathrm{I} 63 \mathrm{~b}$ & 50 & 6.11 & 6.02 & 67.21 \\
\hline 6 & $\mathrm{I} 63 \mathrm{~b}$ & 60 & 6.71 & 6.62 & 73.87 \\
\hline 6 & $\mathrm{I} 63 \mathrm{~b}$ & 65 & 7.31 & 7.21 & 80.52 \\
\hline
\end{tabular}

TABLE 5: Safety evaluation index and standard.

\begin{tabular}{lccc}
\hline Regulation & Beam span & $\begin{array}{c}\text { Index } \\
\text { Rail deflection }\end{array}$ & - \\
Railway track district safety regulation & $1 / 400$ & $10 \mathrm{~mm}$ \\
Railway line repair regulation & - & $11 \mathrm{~mm}$ & - \\
Code for railway track design & - & - & - \\
Code for railway bridge verification & $1 / 200$ & - & $185 \mathrm{MPa}$ \\
Code for design on steel structure of railway bridge & - & $1 / 600$ & $13 \mathrm{~mm}$ \\
Code for design of steel structures & $1 / 600$ & $215 \mathrm{MPa}$ \\
Evaluation standard & & $135 \mathrm{MPa}$ \\
\hline
\end{tabular}

the reinforced system motion can be obtained by applying the previously obtained wheel-rail force histories to the independent reinforced subsystem [20]. In the following, the updated reinforced system motion histories are combined with the track irregularities to form the new excitation to the vehicle subsystem for the next iteration process, until the given error threshold is satisfied.

The train is regarded as several independent vehicle elements with the same speed and interaction among the vehicle elements is ignored. Thus the vehicle-railway coupling system consists of a reinforced system subsystem and several vehicle elements.

The motion equations of the vehicle element $i$ are expressed as

$$
\mathbf{M}_{V i} \ddot{\mathbf{X}}_{V i}+\mathbf{C}_{V i} \dot{\mathbf{X}}_{V i}+\mathbf{K}_{V i} \mathbf{X}_{V i}=\mathbf{F}_{V i}
$$

where $\mathbf{M}_{V i}, \mathbf{C}_{V i}, \mathbf{K}_{V i}$, and $\mathbf{F}_{V i}$ are the mass matrix, damping matrix, stiffness matrix, and force vector of the vehicle element $i$, respectively.

The motion equations of the reinforced system subsystem are expressed as

$$
\mathbf{M}_{B} \ddot{\mathbf{X}}_{B}+\mathbf{C}_{B} \dot{\mathbf{X}}_{B}+\mathbf{K}_{B} \mathbf{X}_{B}=\mathbf{F}_{B}
$$

where $\mathbf{M}_{B}, \mathbf{C}_{B}, \mathbf{K}_{B}$, and $\mathbf{F}_{B}$ are the global mass, damping, and stiffness matrices and the force vector of the reinforced system subsystem, respectively. The former three ones can be obtained by the finite element method or the superposition method; the force vector $\mathbf{F}_{B}$ is the summing effect of the wheel-track interaction forces for all the wheelsets.

To consider the wheel-rail interaction, three assumptions are adopted.

(1) By the Kalker's Linear Theory, the lateral $(Y)$ displacement of the wheelset is the product of the creep coefficient and the wheel-rail relative velocity.

(2) By the wheel-rail corresponding assumption, the wheelset and the rail have the same vertical $(Z)$ and rotational $(U)$ displacement at the wheel-rail contact point.

(3) Each car-body or bogie has 5 independent DOFs in directions $Y, Z, U, V$, and $W$; each wheelset has 1 independent DOF in direction $Y$ and 2 dependent DOFs in directions $Z$ and $U$.

From assumptions above, the wheel-rail interaction force has three components in lateral $(Y)$, vertical $(Z)$, and torsional $(U)$ directions; see Figure 3.

In Figure 3, for an individual wheelset, $P_{1}$ and $P_{2}$ are the vertical interaction force between the bogie and the wheelset; $P_{3}$ and $P_{4}$ are the vertical wheel-rail interaction force; $P_{5}$ is the lateral wheel-rail interaction force; $G$ is the static axle load.

The dynamic equilibrium equations for the vehiclerailway interaction system can be formed by the equations of the vehicle subsystem and the reinforced system subsystem. 
TABLE 6: Results of vehicle-railway dynamic analysis.

\begin{tabular}{|c|c|c|c|c|c|}
\hline Span & Beam size & Velocity/km/h & Acceleration $/ \mathrm{m} / \mathrm{s}^{2}$ & Max. vertical force of wheelset/kN & Min. vertical force of wheelset $/ \mathrm{kN}$ \\
\hline \multirow{4}{*}{$4 \mathrm{~m}$} & \multirow{4}{*}{$63 b$} & 45 & 877.46 & 272.33 & 210.30 \\
\hline & & 50 & 1024.68 & 272.53 & 213.45 \\
\hline & & 55 & 1219.40 & 270.90 & 208.05 \\
\hline & & 60 & 846.97 & 271.99 & 213.56 \\
\hline \multirow{4}{*}{$5 \mathrm{~m}$} & \multirow{4}{*}{$63 b$} & 45 & 816.17 & 302.26 & 193.22 \\
\hline & & 50 & 703.85 & 295.86 & 192.78 \\
\hline & & 55 & 766.77 & 293.04 & 191.94 \\
\hline & & 60 & 904.85 & 285.10 & 185.60 \\
\hline \multirow{4}{*}{$6 \mathrm{~m}$} & \multirow{4}{*}{$63 \mathrm{~b}$} & 45 & 650.14 & 345.29 & ${ }^{*} 156.43^{*}$ \\
\hline & & 50 & 944.35 & 324.93 & ${ }^{*} 153.73^{*}$ \\
\hline & & 55 & 748.13 & 327.33 & ${ }^{*} 171.55^{*}$ \\
\hline & & 60 & 535.23 & 313.00 & ${ }^{*} 168.10^{*}$ \\
\hline \multirow{4}{*}{$7 \mathrm{~m}$} & \multirow{4}{*}{$63 b$} & 45 & 487.92 & 333.37 & ${ }^{*} 175.30^{*}$ \\
\hline & & 50 & 1493.48 & 454.60 & $* 76.06^{*}$ \\
\hline & & 55 & 977.55 & 420.67 & ${ }^{*} 103.67^{*}$ \\
\hline & & 60 & 581.06 & 387.89 & ${ }^{*} 131.90^{*}$ \\
\hline
\end{tabular}

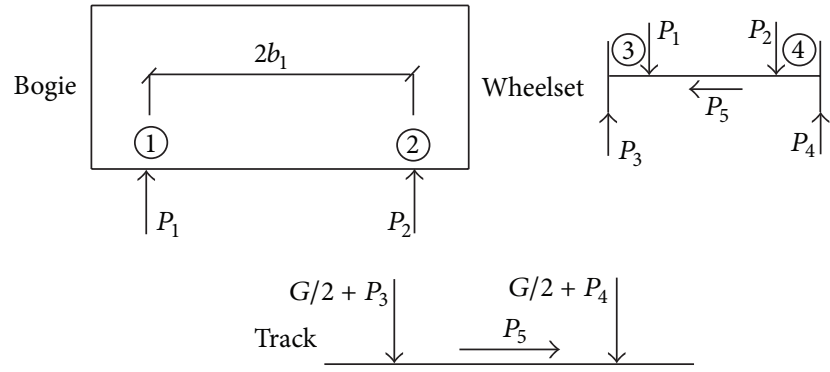

FIgURE 3: Wheel-rail interaction force.

When the direct stiffness method is adopted for the reinforced system, the interaction equations are

$$
\begin{aligned}
& \mathbf{M}_{V 1} \ddot{\mathbf{X}}_{V 1}+\left(\mathbf{C}_{V 1}+\mathbf{C}_{C 1}\right) \dot{\mathbf{X}}_{V 1}+\mathbf{K}_{V 1} \mathbf{X}_{V 1}=\mathbf{F}_{V 1}, \\
& \mathbf{M}_{V 2} \ddot{\mathbf{X}}_{V 2}+\left(\mathbf{C}_{V 2}+\mathbf{C}_{C 2}\right) \dot{\mathbf{X}}_{V 2}+\mathbf{K}_{V 2} \mathbf{X}_{V 2}=\mathbf{F}_{V 2}, \\
& \vdots \\
& \mathbf{M}_{V n} \ddot{\mathbf{X}}_{V n}+\left(\mathbf{C}_{V n}+\mathbf{C}_{C n}\right) \dot{\mathbf{X}}_{V n}+\mathbf{K}_{V n} \mathbf{X}_{V n}=\mathbf{F}_{V n}, \\
& \mathbf{M}_{B} \ddot{\mathbf{X}}_{B}+\mathbf{C}_{B} \dot{\mathbf{X}}_{B}+\mathbf{K}_{B} \mathbf{X}_{B}=\mathbf{F}_{B},
\end{aligned}
$$

where $n$ is the vehicles number of the train. The first $n$ equations in (3) are for the vehicle subsystem, and the last equation is for the reinforced subsystem.

3.2. Model Simplification and Calculation Parameters. Dynamic simulation of railway reinforced system is calculated by vehicle-rail interaction method in the research; it aims to define lower limit of reinforced system stiffness which can ensure train's passing safe. To study dynamic characteristics of railway reinforced system safely, track irregularity must be ignored during the process of calculation; therefore, analyze the dynamic response of railway reinforced system by passing plane train model; then acceleration and wheelset load reduction can be obtained. In the process of calculating acceleration and wheelset load reduction, ignore the longitudinal members, which mean that neglecting the adjacent beam's load sharing from the beam researched is safe; then a model with transverse beams, without longitudinal members, is established. Calculate dynamic response and vertical wheeltrack force of railway reinforced system when the train passes by, so that railway reinforced system's reliability can be evaluated and a suggested solution can be given.

Comparing the weight of locomotive on heavy haul railway, the van's weight per meter is greater, so apply van's weight as load in model. Distance of adjacent clasps of C80 van is $12 \mathrm{~m}$; take $8.2 \mathrm{~m}$ as definite distance; distance of axle is $1.83 \mathrm{~m}$, considering the train whose axle weighing $25 \mathrm{t}$ may pass railway reinforced system; take $25 \mathrm{t}$ as axle load, namely $245.15 \mathrm{kN}$, which means unilateral wheel weighs $122.575 \mathrm{kN}$. In addition, wood blocking weighs $52 \mathrm{~kg} /$ meter, u-bolt weighs $5 \mathrm{~kg} /$ meter, so there is the load of $77 \mathrm{~kg}(52+5 \times 5)$ on each transverse beam in total; this load is distributed on 7 points within the scope of $1.1 \mathrm{~m}$, namely, $11 \mathrm{~kg}$ on each point.

3.3. Calculation Results and Evaluation. Settings of dynamic calculation cases and results are listed in Table 6.

Take the following case as an example: beam size is I63b; span length is $4 \mathrm{~m}$; speed of train is $60 \mathrm{~km} / \mathrm{h}$; the vertical acceleration and vertical wheel-rail force history of train's first wheel are listed in Figures 4 and 5. Indexes of transverse beam varying with velocity under all conditions are listed in Figures 6,7 , and 8 .

In the process of wheelset's moving on rail track, the load of one wheel or both wheels may reduce because of the impact of vibration or lateral force; there are field tests showing that wheels may derail if wheel load reduction is large. Regulations in "code for railway vehicle dynamics performance evaluation and test identification" rule the following: take rate of wheel load reduction as the limit index of wheel load reduction; therefore, use rate of wheel load reduction as control index 


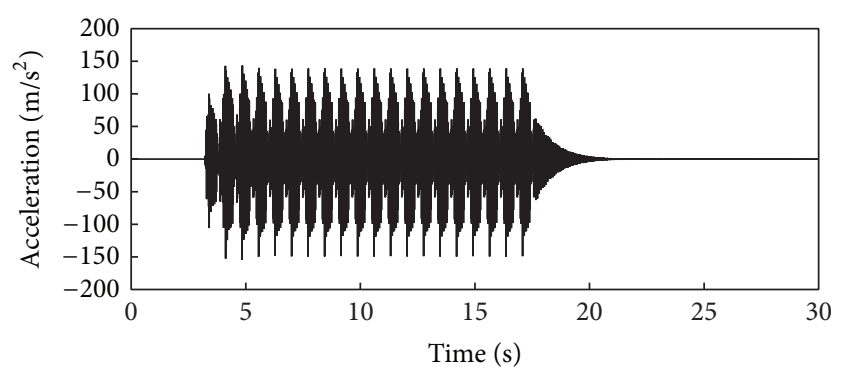

FIGURE 4: Vertical acceleration history of midpoint of beam.

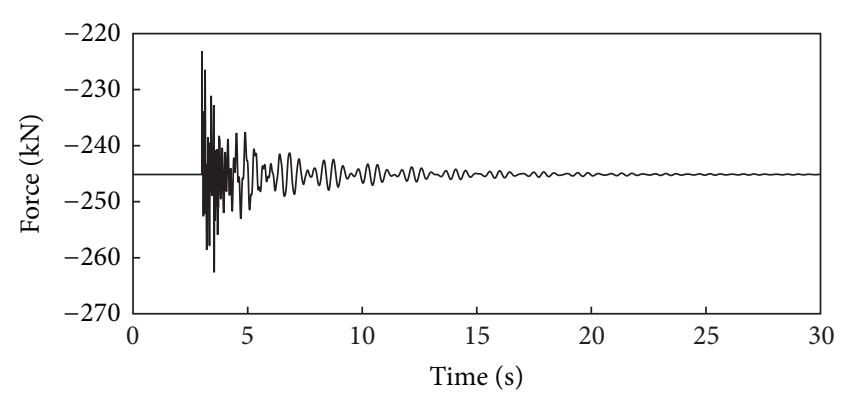

FIGURE 5: Vertical wheel-rail force history of train's first wheel.

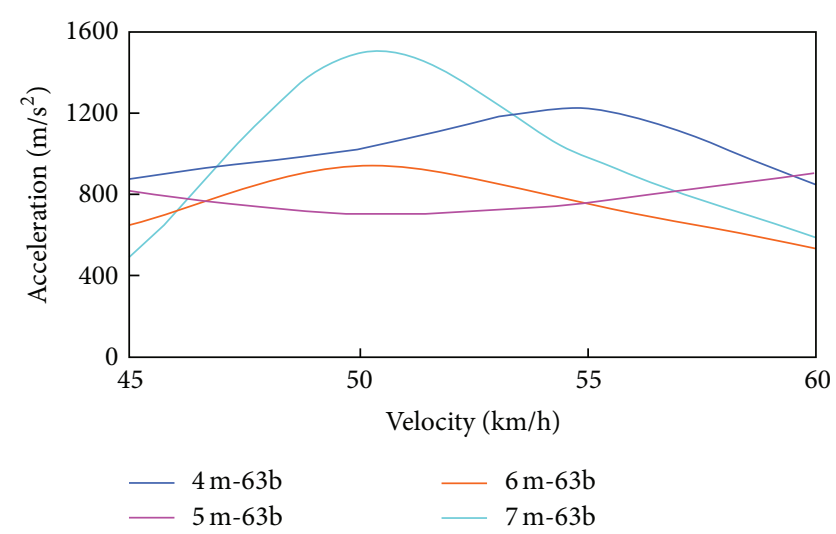

FIGURE 6: Vertical acceleration of midpoint of beam varying with velocity.

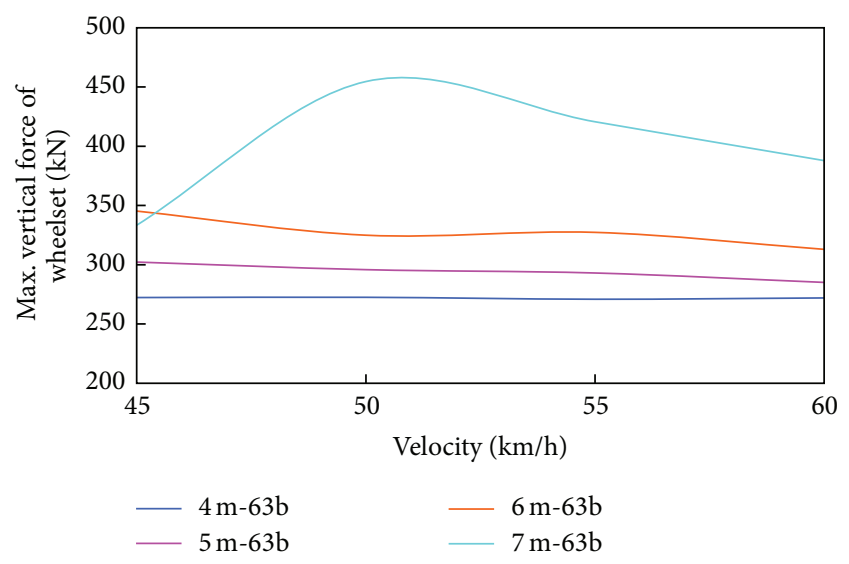

FIGURE 7: Max. vertical force of wheelset varying with velocity.

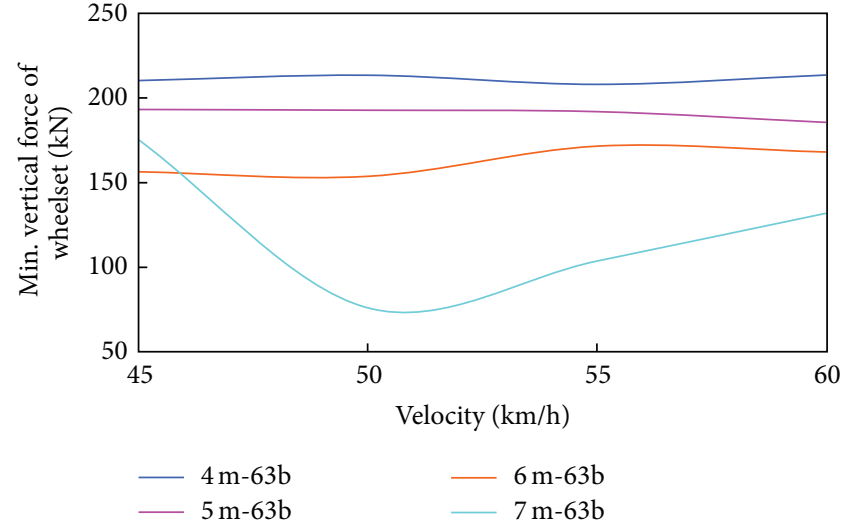

FIGURE 8: Min. vertical force of wheelset varying with velocity.

of dynamic calculation; and establish the standard with reference to bridge vertical rigidity limit of Shinkansen in Japan (recurring rate of wheel load reduction cannot be larger than 0.25 ; instantaneous rate of wheel load reduction cannot be larger than 0.375); in consideration of safety, take 0.25 as safety standard, so the safe lower limit of wheel load is $184 \mathrm{kN}$, that is $25000 \mathrm{~kg} \times$ gravity acceleration $\times(1-0.25)$, which means if instantaneous vertical wheel force is less than $184 \mathrm{kN}$, there will be high risk when a train passes the railway reinforced system. Meantime, dynamic calculation can also obtain acceleration of railway reinforced system; whereas there are no relative regulations, acceleration will not be taken as evaluation index. Therefore, among the results listed in Table 6, the results whose minimum vertical load of wheelset is less than $184 \mathrm{kN}$ will be evaluated as unqualified, expressed by $* *$ aside, and conditions whose results fulfill standard under all kinds of speed are marked with bold font.

It can be seen from calculation results that, if we take I63b as transverse beam and the span length is $6 \mathrm{~m} / 7 \mathrm{~m}$, the value of vertical force of wheelset under all speed is less than limit value, which means there is high risk of derailment or overturn for train; if we take I63b as transverse beam and the span length is $4 \mathrm{~m} / 5 \mathrm{~m}$, the value of vertical force of wheelset under all speed can meet the requirement of evaluation standard. Therefore, based on dynamic calculation, the following plan of railway reinforced system is suggested: take I63b as transverse beam, ensure the length of span is less than $5 \mathrm{~m}$; if length of span exceeds $5 \mathrm{~m}$, supporting measures should be taken under midspan of transverse beam.

Although acceleration of rail is not taken as evaluation index, it can describe the vibration amplitude of railway reinforced system objectively. It can be seen from Figure 6 that, as indexes varying in different cases, acceleration peak appears in scope of $40 \sim 55 \mathrm{~km} / \mathrm{h}$ in every case; this phenomenon is caused by resonance of vehicle and railway reinforced system. Therefore, to minimize the impact of resonance, it is suggested that a number of damper cushions should be taken in railway reinforced system.

\section{Conclusions}

The conditions of railway reinforced system are calculated by both static and dynamic analysis; the results are evaluated 
by the proposed standard; conclusions are summarized as follows.

(1) Compared with simplified model, the optimized model simulated the conditions of construction site better, so that results are improved. The calculated result and the railway reinforcement design are safer by adopting the proposed standard in both the static and dynamic analysis.

(2) The dynamic analysis based on vehicle-railway coupling theory can simulate the dynamic response history of railway reinforced system under the moving load of train. The rail acceleration, offloading factor, the vibration, and resonance phenomenon of railway reinforced system are calculated. The mentioned items affect the safety of railway reinforced system; thus it is necessary to adopt the dynamic analysis in the designing of railway reinforced system.

(3) The evaluation standards of static and dynamic calculation should be mutual complement, so that a complete evaluation system of railway reinforced system should be formed by both the static and the dynamic calculation to evaluate the design of railway reinforced system; the plan fulfills both the static and dynamic requirement and is safe and suitable one.

\section{Conflict of Interests}

The authors declare that there is no conflict of interests regarding the publication of this paper.

\section{Acknowledgments}

The research is sponsored by the Major State Basic Research Development Program of China ("973" Program: 2013CB036203) and the Fundamental Research Funds for the Central Universities (Grant no. 2013JBM011)

\section{References}

[1] B. Yu, Z. Z. Yang, and B. Z. Yao, "Bus arrival time prediction using support vector machines," Journal of Intelligent Transportation Systems: Technology, Planning, and Operations, vol. 10, no. 4, pp. 151-158, 2006

[2] B. Yu, W. H. K. Lam, and M. L. Tam, "Bus arrival time prediction at bus stop with multiple routes," Transportation Research C: Emerging Technologies, vol. 19, no. 6, pp. 1157-1170, 2011.

[3] B. Yu, Z. Yang, K. Chen, and B. Yu, "Hybrid model for prediction of bus arrival times at next station," Journal of Advanced Transportation, vol. 44, no. 3, pp. 193-204, 2010.

[4] B. Yu, Z. Z. Yang, and S. Li, "Real-time partway deadheading strategy based on transit service reliability assessment," Transportation Research A, vol. 46, no. 8, pp. 1265-1279, 2012.

[5] G. Q. Meng, "Analysis of reinforcement system for jack-in construction of vertical and lateral beams of frame bridge of existing railway line," Journal of Railway Engineering Society, vol. 106, no. 7, pp. 42-47, 2007.

[6] Y. P. Ding, Y. B. Wang, and Y. B. Qu, "Analysis of the load bearing capacity of reinforcement system with space structure for track on i-beam of frame bridge," Journal of Railway Engineering Society, vol. 132, no. 9, pp. 42-45, 2009.

[7] G. Diana and F. Cheli, "Dynamic interaction of railway systems with large bridges," Vehicle System Dynamics, vol. 18, no. 1-3, pp. 71-106, 1989.

[8] L. Frýba, Vibration of Solids and Structures under Moving Loads, Thomas Telford, London, UK, 1999.

[9] X. Z. Li, J. Cai, and S. Z. Qiang, “Train runability of the schemed Beijing-Shanghai high-speed railway on the Nanjing Yangtzeriver bridge," Engineering Mechanics, no. 6, pp. 86-92, 2003 (Chinese).

[10] N. Zhang and H. Xia, "Dynamic analysis of coupled vehiclebridge system based on inter-system iteration method," Computers and Structures, vol. 114, pp. 26-34, 2013.

[11] Y. B. Yang, J. D. Yau, L. C. Hsu, "Vibration of simple beams due to trains moving at high speed," Engineering Structures, vol. 19, no. 11, pp. 936-944, 1997.

[12] X. R. Guo, Z. M. Deng, and H. Luo, "Dynamic responses of time-dependent system of Tianxingzhou Bridge and train under wind load," in Proceedings of the Environmental Vibrations: Prediction, Monitoring, Mitigation and Evaluation, pp. 1208-1213, Beijing, China, 2009.

[13] P. T. Torstensson, J. C. O. Nielsen, and L. Baeza, "Dynamic traintrack interaction at high vehicle speeds-modelling of wheelset dynamics and wheel rotation," Journal of Sound and Vibration, vol. 330, no. 22, pp. 5309-5321, 2011.

[14] J. Fayos, L. Baeza, F. D. Denia, and J. E. Tarancón, “An Eulerian coordinate-based method for analysing the structural vibrations of a solid of revolution rotating about its main axis," Journal of Sound and Vibration, vol. 306, no. 3-5, pp. 618-635, 2007.

[15] M. M. Gao, Study on Train-Track-Bridge Coupling Vibration and Train Running on High-Speed Railway, China Academy of Railway Science, Beijing, China, 2001.

[16] G. H. Li, Stability and Vibration of Bridge Structures, China Railway Publishing, 1996.

[17] Y. Yang and J. Yau, "Vehicle-bridge interaction element for dynamic analysis," Journal of Structural Engineering, vol. 123, no. 11, pp. 1512-1518, 1997.

[18] R. Clough and J. Penzien, Dynamics of Structures, Computers and Structures, Berkeley, Calif, USA.

[19] W. M. Zhai, Vehicle-Track Coupling Dynamics, China Railway Publishing, 2002.

[20] N. Zhang, Z. Fang, H. Xia, and G. J. Sun, "An inter-system iteration solution for vehicle-bridge coupling model and its application," in Proceedings of the 1st international conference on Advances in Interaction and Multiscale Mechanics (AIMM '10), May 2010. 


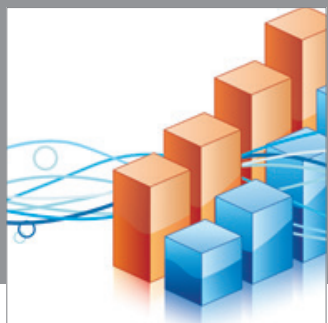

Advances in

Operations Research

mansans

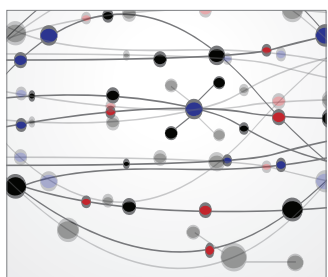

The Scientific World Journal
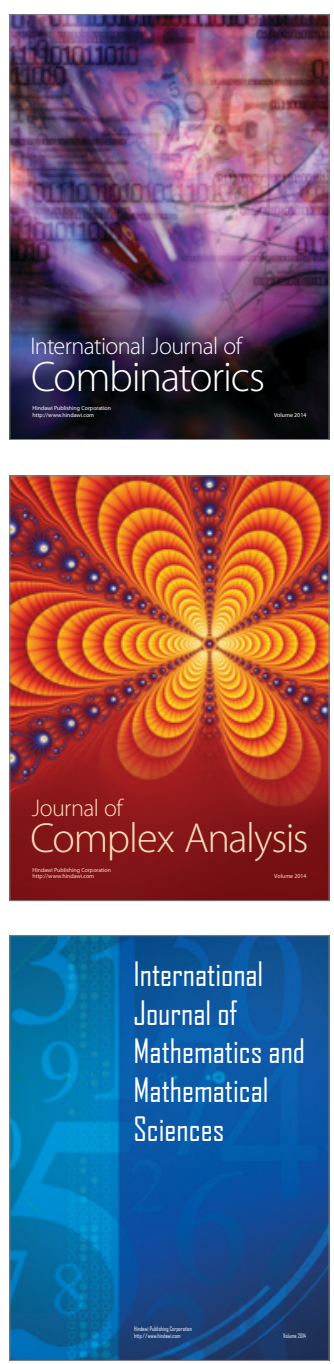
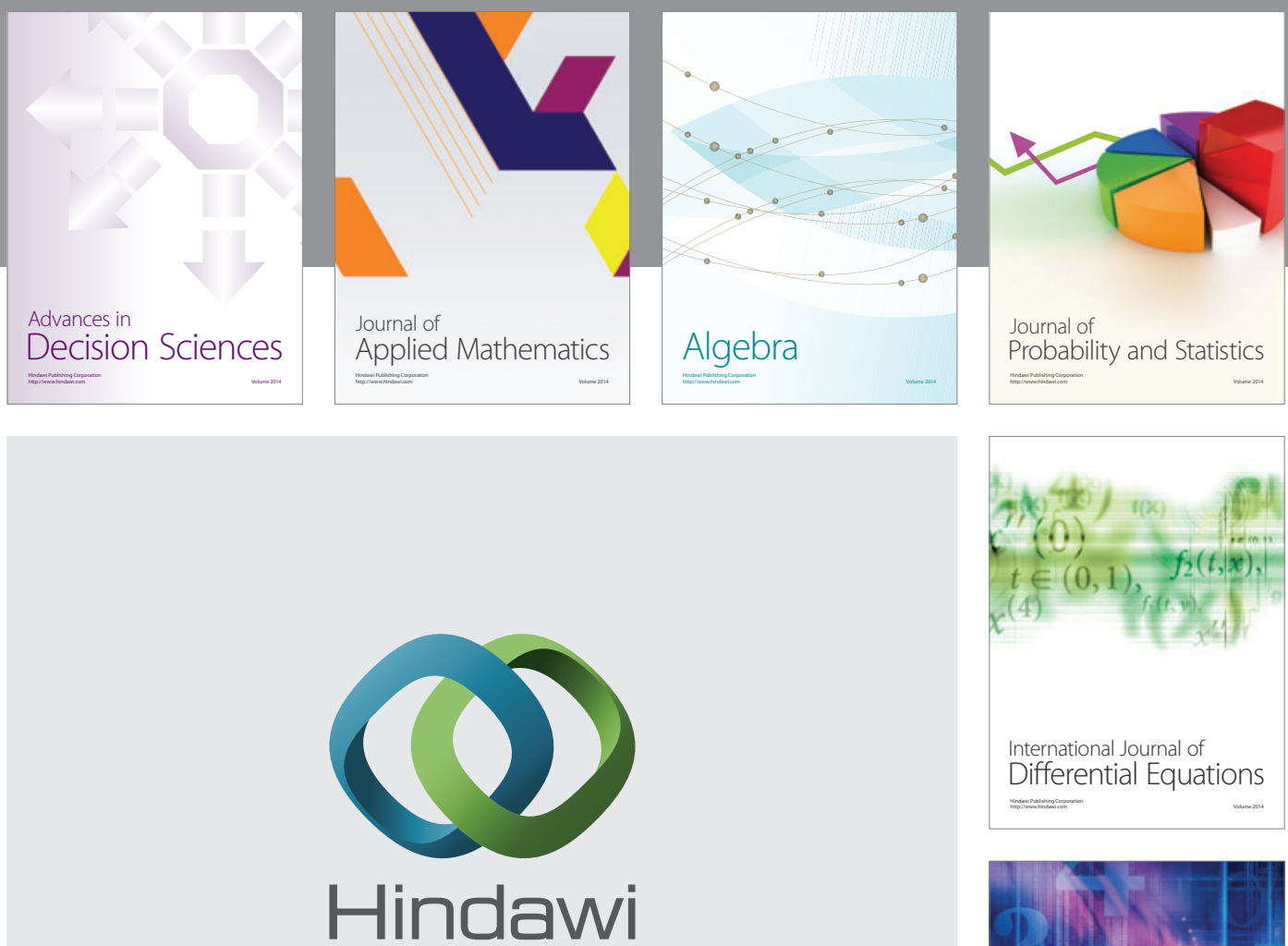

Submit your manuscripts at http://www.hindawi.com
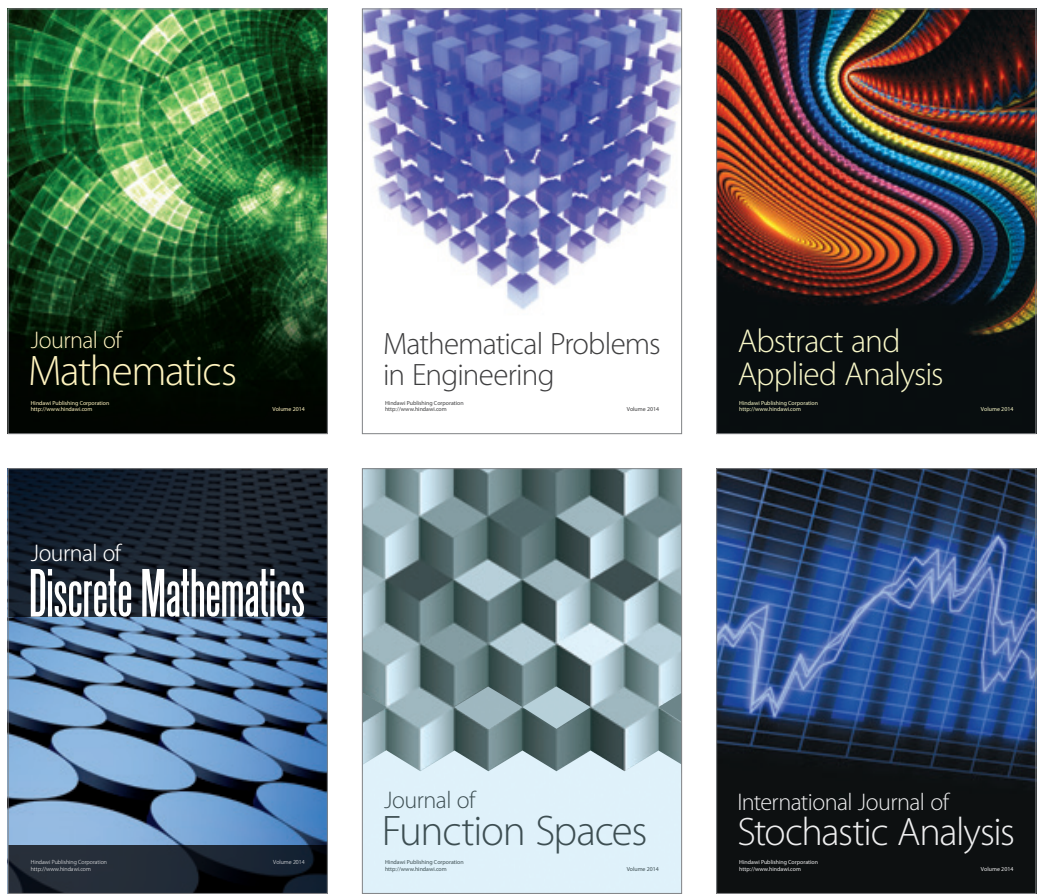

Journal of

Function Spaces

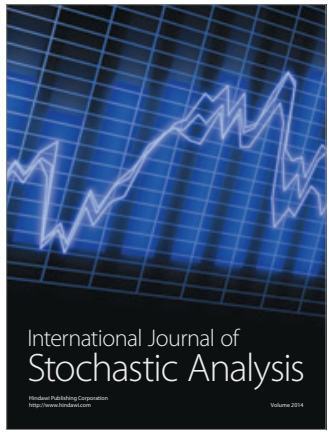

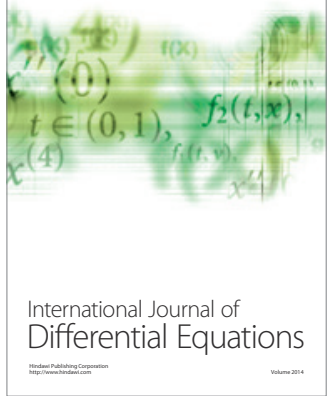
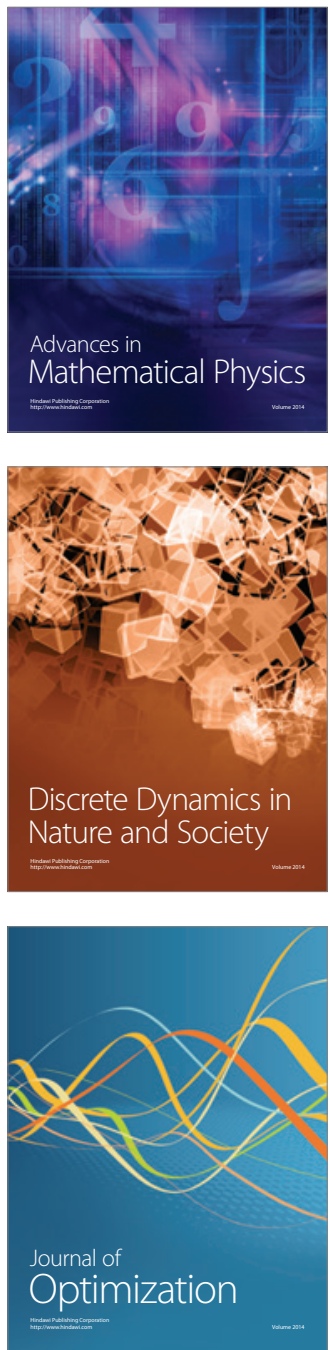